\title{
Application of clay minerals in remediation of heavy metal pollution in soil
}

\author{
Sun Yingying ${ }^{1,2,3,4,{ }^{*}}$, Zhang Baoqiang ${ }^{1,2,3,4}$, Wei Yang ${ }^{1,2,3,4}$ \\ ${ }^{1}$ Shaanxi Provincial Land Engineering Construction Group Co., Ltd, Xi'an 710075, China \\ ${ }^{2}$ Institute of Land Engineering and Technology, Shaanxi Provincial Land Engineering Construction \\ Group Co., Ltd, Xi'an 710075, China \\ ${ }^{3}$ Key Laboratory of Degraded and Unused Land Consolidation Engineering, the Ministry of Natural \\ Resources, Xi'an 710075, China \\ ${ }^{4}$ Shaanxi Provincial Land Consolidation Engineering Technology Research Center, Xi'an 710075, \\ China
}

\begin{abstract}
In modern times where heavy metal pollution in soil is becoming more and more serious, the new natural non-polluting remediation methods represented by clay mineral materials have attracted more and more attention in the industry.In this paper, the research progress on the types and basic characteristics of clay mineral materials, the effect and mechanism of remediation of heavy metal pollution in soil at home and abroad was comprehensively discussed. The deficiencies of relevant studies were also summarized, and the future research trend was predicted.
\end{abstract}

Keywords: Clay mineral; Heavy metal pollution; Repair mechanism

Clay mineral remediation is one of the hot methods for heavy metal pollution remediation in recent years. Concrete by adding different types of mineral materials, to adjust and change of heavy metals in the soil physical and chemical properties, make its REDOX, precipitation, adsorption, chelation, suppress, or a series of reactions such as antagonism, reduce its biological effectiveness and mobility in soil environment, thus reducing the heavy metal toxicity of plants and animals (Aroua et al., 2008; Kabbashi et al., 2009). Because of the advantages of low investment, high efficiency and simple operation, this method has a good application prospect for the remediation of large area contaminated soil.

\section{Basic properties of clay minerals}

Clay minerals are the main minerals that make up claystone and soil. The common clay minerals include kaolinite, montmorillonite and illite. Basic properties including mineral surface adsorption clay mineral materials, structural adjustment, channel filtration, ion exchange, physical effect, chemical activity, nanometer effect and biological interactions (Lu, 2001), so the clay mineral materials besides has the general characteristics of environment mineral materials, also have the function that repair environment, in the heavy

* Corresponding author: Sunyy526@163.com 
metal pollution in soil with super self-purification ability (Xu etc., 2017). This type of mineral contains aquifer silicates whose main structural units are 2-dimentional silica tetrahedron and 2-dimentional aluminum or magnesium-oxygen-hydrogen octahedron.

Surface charges of soil particles play an important role in the way of binding between pollutants and soil particles, and soil charges are mainly derived from clay mineral colloids (Zhuang et al., 2002).In the structural unit layer of clay minerals, $\mathrm{Si}^{4+}$ in the silicon-oxygen tetrahedron may be replaced by $\mathrm{Al}^{3+}$, and $\mathrm{Al}^{3+}$ in the octahedron may be replaced by $\mathrm{Mg}^{2+}$ and $\mathrm{Fe}^{2+}$. At this time, negative charge appears in the structural unit layer. In order to balance the excess negative charge, interlayer cation must appear. Interlamellar cations of clay minerals are of two types: "fixed" and "exchangeable". The heavy metal lead present in the soil can be fixed by the excess negative charge in the clay minerals. Therefore, clay mineral materials can play an effective role in the treatment and remediation of air pollution, water pollution and soil pollution.

\section{Mechanism of clay minerals used in remediation of heavy metal pollution in soil}

Lou et al. (2008) and Xu et al. (2012) confirmed the great research value and application prospect of various clay minerals by studying the remediation mechanism, application effect, application influencing factors and modification methods of heavy metal contaminated soil (Liu et al., 2011).Montmorillonite, attapulgite, zeolite, kaolinite, sepiolite, vermiculite and illite are common clay minerals used for remediation of heavy metal pollution in soil and as fixators for fixing heavy metals (Covelo et al., 2007a).Bradl (2002) and Basta (2001) confirmed that clay minerals are one of the main components of heavy metals adsorption and passivation in soil, and the passivation effect is significant. Soil fixation of different heavy metals was affected by clay minerals in the soil (Covelo et al., 2007).Clay minerals, with their large specific surface area, strong mechanical stability, abundant reserves, low price, stable chemical properties, and environmental friendliness, are gradually applied in the research and practice of soil heavy metal pollution treatment (Shang, 2008).

The adsorption of heavy metal ions by different environmental mineral materials is controlled by such factors as the distribution of layer charge of environmental mineral materials, the electricity price of heavy metal ions, the heat of hydration and the ion radius. Through adsorption experiments, it was found that montmorillonite, kaolinite and illite had selective adsorption of $\mathrm{Cu}^{2+}, \mathrm{Pb}^{2+}, \mathrm{Zn}^{2+}, \mathrm{Cd}^{2+}$, and $\mathrm{Cr}^{3+}$ heavy metal ions, montmorillonite had good adsorption of $\mathrm{Cu}^{2+}$ and $\mathrm{Cr}^{3+}$, and kaolinite and illite had strong affinity for $\mathrm{Pb}^{2+}$, $\mathrm{Zn}^{2+}$ and $\mathrm{Cd}^{2+}$ (He et al. 1999). The research results of Liu et al. (2011) showed that carbonate mineral materials mainly composed of limestone and dolomite mainly increase the fixation of heavy metals by changing the $\mathrm{pH}$ of soil, thereby increasing the formation of insoluble carbonate rock precipitation between soil components and heavy metal ions. However, silicate minerals such as lithium pyroxene, feldspar, beryl, quartz, etc. can improve the $\mathrm{pH}$ of soil under appropriate conditions, make heavy metals form precipitation, and form certain adsorption effects on heavy metal ions $\left(\mathrm{Pb}^{2+}, \mathrm{Cu}^{2+}, \mathrm{Fe}^{3+}, \mathrm{Ca}^{2+}\right)$ through surface chelation and exchange. Among them, lithium pyroxene has a strong metal cation adsorption capacity, and metal cation is mostly adsorbed at ion exchange sites. The structure of feldspar, quartz and beryl is mainly tetrahedron, and an oxygen of the tetrahedron coordinates with the adsorbed heavy metal ions (Jia et al., 2001). 


\section{Limitations of clay minerals in remediation of heavy metal pollution in soil}

At present the obstacle of soil mineral material repair mainly concentrated in the regulation of the proportion of sand stick, crumb structure of the soil water form, water holding capacity, soil $\mathrm{pH}$, improved the physical and chemical properties such as, and repair the common mechanism of soil heavy metal pollution is through to improve the soil $\mathrm{pH}$, encourage active strong heavy metal ions and $\mathrm{CO} 32-$, $\mathrm{PO} 43-$ and $\mathrm{OH}-$ generated precipitation. However, due to the buffer capacity of the soil itself, the $\mathrm{pH}$ value will gradually decrease, so the heavy metals that have been passivated are easy to be reactivated and cause secondary pollution. Moreover, the passivators used are mostly initial raw materials, which have many drawbacks in the process of soil remediation. Such as lime passivation agent is too alkaline, easy to harm the soil microbial activity and the normal growth of crops, and for a long time adding will also cause soil hardening and micronutrient deficiency. The temporarily adsorbed heavy metals are vulnerable to the influence of soil acidity, competitive ions, REDOX potential and other factors, so as to re-release or form biodegradable forms (Wang et al., 2009). The clay minerals such as montmorillonite and sepiolite have single composition and low activity of effective components, so the application amount is too large. Although peat, lignite, weathered coal and other organic minerals can supplement soil organic matter and form complexes with heavy metals, the degradation of organic substances may cause the re-release of heavy metals, resulting in secondary pollution. Moreover, organic minerals are not very active, and such passivation agents are acidic, which is not suitable for acid soil remediation (Chen et al., 2008).

Above all, the clay minerals have become the basic conditions for high quality heavy metal contaminated soil repair material, can fundamentally improve the quality of soil, the reduction of the soil ecological nature, thus improving the holding of heavy metal pollution of soil and purify ability, reduce the uptake of metals by plants, ensure the safety of agricultural products, and large reserves, low cost, will become the future development direction and trend of green materials. However, there are still some problems to be solved in its application, so the future research should be strengthened.

\section{Acknowledgement}

This study was supported by Fund Project of Shaanxi Key Laboratory of Land Consolidation (2018-JC16) and the Research Project of Shaanxi Provincial Land Engineering Construction Group in China (DJNY2020-18).

\section{References}

1. Aroua M K, Leong S P P, Teo L Y, et al. Real-time determination of kinetics of adsorption of lead (II) onto palm shell-based activated carbon using ion selective electrode, Bio resource Technology. 99 (2007) 5786-5792.

2. Basta N T, Gradwohl R, Snethen K L, et al. Chemical immobilization of lead, zinc, and cadmium in smelter-contaminated soils using biosolids and rock phosphate, Journal of Environmental Quality. 30 (2001) 1222-1230.

3. Bradl H B. Adsorption of heavy metal ions on clays .In Hubbard A T (Ed.), Encyclopedia of Surface and Colloid Science .New York: Marcel Dekker Ltd, 2002, 373-384. 
4. Chen Y Q, Dong Y H. Progress of research and utilization of soil amendments, Ecology and Environment. 17 (2008) 1282-1289.

5. Covelo E F, Vega F A, Andrade M L. Simultaneous sorption and desorption of Cd, $\mathrm{Cr}, \mathrm{Cu}, \mathrm{Ni}, \mathrm{Pb}$, and $\mathrm{Zn}$ in acid soils I. Selectivity sequences, Journal of Hazardous Materials, 147 (2007) 852-861.

6. Covelo E F, Vega F A, Andrade M L. Competitive sorption and desorption of heavy metals by individual soil components, Journal of Hazardous Materials. 140 (2007) 308-315.

7. He H P, Guo J G, Xie X D, et al. Experimental studies on the selective adsorption of $\mathrm{Cu}^{2+}, \mathrm{Pb}^{2+}, \mathrm{Zn}^{2+}, \mathrm{Cd}^{2+} \mathrm{Cr}^{3+}$ ions on montmorillonite, illite and kaolinite and the influence of medium conditions, Acta Mineralogica Sinica. 19 (1999) 231-235.

8. Jia M X, Sun C Y. study on adsorption behavior of metal ions on some silicate minerals, Mining and metallurgy. 10 (2001) 25-30.

9. Kabbashi N A, Atieh M A, Al-Mamun A, et al. Kinetic adsorption of application of carbon nanotubes for $\mathrm{Pb}$ (II) removal from aqueous solution, Acta Scientiae Circumstantiae. 21 (2009) 539-544.

10. Liu Y, Dong Y H, Hang X S, et al.Advances in application of environmental mineral materials in soil environment remediation, Acta Pedologica Sinica. 48 (2011) 629-638.

11. Lou Y H, Zhuge Y P, Gu J G, Chao Y. Research progress of remedying the heavy metal contaminated soils with clay minerals, Shandong agriculture sciences. (2008) 68-72.

12. Lu A H. Basic properties of environmental mineral materials: natural self-purification of inorganic minerals, Acta oetrologica et mineralogical. 20 (2001) 371-381.

13. Shang P, Shen J F, Zhao R H. Environmental mineral materials. Beijing: Chemical Industry Press, 2008.

14. Wang L Q, Luo L, Ma YB, et al. In situ immobilization of heavy metals-contaminatedsoils: a review, Chinese journal of applied ecology. 20 (2009) 1214-1222.

15. Xu C, Chen B R, Lv G M, et.al. research progress of chemical fixation of heavy metals in soil by silicate and phosphate, Environmental science and management. 37 (2012) 164-168.

16. Xu Y, Liang X F, Peng L, et al. Research advances on immobilization remediation of heavy metal contaminated farmland soil with clay minerals, Shandong Agriculture sciences. 49 (2017) 156-162.

17. Zhuang J, Yu G. R. Effects of surface coatings on electrochemical properties and contaminant sorption of clay minerals, Chemosphere. 49 (2002) 619-628. 